\title{
Intensive Care Society's APACHE II study in Britain and Ireland-I: Variations in case mix of adult admissions to general intensive care units and impact on outcome
}

\author{
K M Rowan, J H Kerr, E Major, K McPherson, A Short, M P Vessey
}

Department of Public Health and Primary Care, University of Oxford, Gibson Laboratories Building, Radcliffe Infirmary, Oxford OX2 6HE

KM Rowan, research fellow M P Vessey, professor of social and community medicine

Nuffield Department of Anaesthetics, University of Oxford, Radcliffe

Infirmary, Oxford OX2 6HE

J H Kerr, consultant anaesthetist

Intensive Therapy Unit, Morriston Hospital, Swansea SA9 6NL

E Major, director

Health Promotion Sciences Unit, Department of Public Health and Policy, London School of Hygiene and Tropical Medicine, London WC1E 7HT $\mathrm{K}$ McPherson, professor of public health epidemiology

Intensive Care Unit, Broomfield Hospital, Chelmsford, Essex

CM1 5ET

A Short, director

Correspondence to: Dr Rowan.

BMf 1993;307:972-7

\begin{abstract}
Objectives-To describe the extent of variation in the case mix of adult admissions to general intensive care units in Britain and Ireland and investigate the impact of such variation on outcome.

Design-Prospective, cohort study of consecutive admissions to intensive care units.

Setting - 26 general intensive care units in Britain and Ireland.

Subjects-9099 admissions to the intensive care units studied.

Main outcome measure-Death or survival at discharge before and after adjustment of case mix (age, history of chronic conditions, surgical status, diagnosis, and severity of illness) according to the APACHE II method.

Results-Important differences in case mix were found, with large variations between the units. Hospital mortality was significantly associated with most of the case mix factors investigated.

Conclusions-Comparing crude death rates in hospital between intensive care units may be misleading indicators of performance. The collection of data on case mix needs to be standardised and differences in case mix adjusted for when comparing outcome between different intensive care units.
\end{abstract}

\section{Introduction}

In 1988 a multidisciplinary panel convened by the King's Fund Centre for Health Services Development produced a consensus statement which highlighted the lack of and need for information on intensive care in the United Kingdom and called for a substantial programme of research. ${ }^{1}$

For comparisons of outcome from different intensive care units to be meaningful differences in the case mix of patients (age, diagnosis, severity of illness, and history of chronic conditions) must be taken into account. $^{2-10}$ The extent of differences in case mix between adult, general intensive care units in the United Kingdom is, however, unknown as published studies have been limited to one or, at most, two units. ${ }^{11-17}$ When these studies are compared case mix varies considerably, although data from these studies are not contemporaneous and the methods of measuring the case mix varied.

As part of a prospective cohort study of the outcome in adult patients receiving intensive care in Britain and Ireland data on case mix were collected in 26 units. This paper describes the differences in case mix and their relation to outcome.

\section{Methods}

Selected mixed medical and surgical intensive care units were invited to participate in one of the two recruitment phases of the study (phase I: between October and December 1987, phase II: between January and April 1989). Selection of intensive care units was influenced by the need to ensure $(a)$ a wide geographical spread, $(b)$ an equal distribution of teach- ing and non-teaching hospitals, and $(c)$ a wide range of unit size. After selection the criteria for participation were that the unit director (or other senior person) must (a) show a strong commitment to participate, $(b)$ agree to conform strictly to the study protocol, (c) collect data prospectively on consecutive admissions for at least one year, and (d) be directly responsible for the collection and quality of the data.

Patients were excluded $(a)$ if they had been admitted for administrative reasons (that is, they did not need intensive care), (b) if they had been admitted for organ donation alone (that is, they were brain stem dead on entry to the unit), (c) if they were under 16 years old, and $(d)$ if they had been admitted from the coronary care unit because the specialist unit was full.

Data on case mix were collected under six main headings: sociodemographic factors (age, sex, race); a history of chronic conditions; surgical status; diagnosis; other active problems; and severity of illness (acute physiological state). History of chronic conditions, surgical status, diagnosis, and severity of illness were measured according to the acute physiology and chronic health evaluation method (APACHE II) ${ }^{4}$ and other active problems according to the mortality prediction model method.1819 Additional, more detailed, unpublished guidelines on data definition were obtained from the developers of APACHE II and the mortality prediction model and were included in a manual on how to complete the questionnaire, which was given to all participating units.

\section{APACHE II METHOD}

The precise definitions used and modifications introduced to the APACHE II method for use in Britain and Ireland are listed in the appendix. For each patient up to three possible values (initial, highest, and lowest) were recorded for each of the 12 physiological variables constituting the acute physiology score. The initial value was recorded from the first test result available in the time up to one hour before and two hours after the start of intensive care treatment. Highest and lowest values were recorded from the results of tests during the first 24 hours of intensive care treatment exclusive of the test result recorded as the initial value. All values were recorded as raw data. For patients who died or were discharged from the intensive care unit within 24 hours the initial, highest, and lowest values were recorded for the time before death or discharge.

Missing physiological values were assumed to be normal and assigned zero points. The acute physiology score was calculated as the sum of the points for the 12 variables. The APACHE II score was calculated as the sum of the acute physiology score plus the points for age and history of chronic conditions (appendix).

Forty one individual diagnostic categories for use in this study were derived from the list of seven primary organ systems and 36 precipitating factors in the original American method (appendix, table X). Patients were assigned to one of these categories according to the principal reason for intensive care treatment. If none was applicable patients were assigned to a general, system diagnostic category. To ensure con- 
sistency in the diagnostic classification one of us (JHK, an experienced clinician) checked and recoded where necessary each patient's diagnostic categorisation. In addition, each patient was assigned an American diagnostic code for their primary diagnosis and for any concurrent diagnoses reported.

\section{MORTALITY PREDICTION MODEL}

Data affirming whether (a) malignant cancer was an active medical problem within six months of the intensive care unit admission, $(b)$ infection was probable at intensive care unit admission, (c) cardiopulmonary resuscitation was undertaken within 24 hours of the intensive care unit admission, and (d) the patient had been previously admitted to an intensive care unit within the previous six months were collected according to the definitions provided by the mortality prediction model. ${ }^{18} 19$ Probable infection was recorded when cultures, Gram staining, or radiography had been ordered to confirm a suspected infection; there was evidence of gross purulence; therapeutic antibiotics had been administered at the start of intensive care; or extensive soft tissue injuries or open wounds were present in patients with multiple trauma. Cardiopulmonary resuscitation included chest compressions, defibrillation, and cardiac massage. A previous admis-

TABLE I-Distribution of admissions between 26 intensive care units in Britain and Ireland

\begin{tabular}{lccc}
\hline $\begin{array}{l}\text { Intensive } \\
\text { care unit } \\
\text { (case No) }\end{array}$ & $\begin{array}{c}\text { Total No of } \\
\text { admissions during } \\
\text { recruitment } \\
\text { period }\end{array}$ & $\begin{array}{c}\text { Estimated } \\
\text { No of } \\
\text { admissions } \\
\text { per year }\end{array}$ & $\begin{array}{c}\text { No of } \\
\text { admissions } \\
\text { included in } \\
\text { analyses (\%) }\end{array}$ \\
\hline 1 & 394 & 219 & $337(85 \cdot 5)$ \\
2 & 520 & 288 & $429(82 \cdot 5)$ \\
3 & 786 & 432 & $581(73 \cdot 9)$ \\
4 & 636 & 352 & $526(82 \cdot 7)$ \\
5 & 298 & 278 & $227(76 \cdot 2)$ \\
6 & 178 & 179 & $160(89 \cdot 9)$ \\
7 & 317 & 297 & $253(79 \cdot 8)$ \\
8 & 327 & 327 & $283(86 \cdot 5)$ \\
9 & 104 & 288 & $102(98 \cdot 1)$ \\
10 & 265 & 251 & $219(82 \cdot 6)$ \\
11 & 441 & 409 & $351(79 \cdot 6)$ \\
12 & 596 & 479 & $389(65 \cdot 3)$ \\
13 & 310 & 265 & $276(89 \cdot 0)$ \\
14 & 207 & 167 & $171(82 \cdot 6)$ \\
15 & 439 & 407 & $331(75 \cdot 4)$ \\
16 & 338 & 341 & $251(74 \cdot 3)$ \\
17 & 305 & 283 & $237(77 \cdot 7)$ \\
18 & 232 & 233 & $188(81 \cdot 0)$ \\
19 & 170 & 128 & $136(80 \cdot 0)$ \\
20 & 822 & 807 & $725(88 \cdot 2)$ \\
21 & 288 & 291 & $221(76 \cdot 7)$ \\
22 & 556 & 308 & $388(69 \cdot 8)$ \\
23 & 645 & 358 & $494(76 \cdot 6)$ \\
24 & 886 & 491 & $621(70 \cdot 1)$ \\
25 & 594 & 330 & $460(77 \cdot 4)$ \\
26 & 958 & 531 & $799(83 \cdot 4)$ \\
\hline Total & 11612 & & $9155(78 \cdot 8)$ \\
\hline & & &
\end{tabular}

TABLE II-Sociodemographic characteristics, surgical status, history of chronic conditions, and coexisting active conditions in 9099 patients admitted to 26 intensive care units with range across units

\begin{tabular}{|c|c|c|c|}
\hline & \multirow{2}{*}{$\begin{array}{c}\text { Overall } \\
(n=9155)\end{array}$} & \multicolumn{2}{|c|}{ Range across units } \\
\hline & & Highest & Lowest \\
\hline \multicolumn{4}{|l|}{ Sociodemographic characteristics: } \\
\hline Mean age (years) & $56 \cdot 3(9155)$ & $63 \cdot 2(102)$ & $48 \cdot 5(389)$ \\
\hline Female (\%) & $40.0(3660)$ & $48 \cdot 1(136 / 283)$ & $27 \cdot 6(200 / 725)$ \\
\hline White race (\%) & $97 \cdot 2(8898)$ & $100 \cdot 0(494 / 494)$ & $83 \cdot 3(189 / 337)$ \\
\hline \multicolumn{4}{|l|}{ Surgical status: } \\
\hline Surgical (\%) & $56 \cdot 8(5203)$ & $77 \cdot 0(558 / 725)$ & $30.6(67 / 219)$ \\
\hline Emergency surgical (\%) & $25 \cdot 6(2339)$ & $54 \cdot 7(151 / 276)$ & $12 \cdot 8(13 / 102)$ \\
\hline \multicolumn{4}{|l|}{ History of chronic conditions (\%): } \\
\hline Any present & $22 \cdot 2(2035)$ & $55 \cdot 0(138 / 251)$ & $6 \cdot 4(40 / 621)$ \\
\hline Cardiovascular & $9 \cdot 4(860)$ & & \\
\hline Respiratory & $8 \cdot 5(774)$ & & \\
\hline Immune & $3.4(308)$ & & \\
\hline Renal & $2 \cdot 3(214)$ & & \\
\hline Hepatic & $1.6(146)$ & & \\
\hline \multicolumn{4}{|l|}{ Coexisting active conditions (\%): } \\
\hline Malignant cancer & $16.4(1500)$ & $28 \cdot 1(71 / 253)$ & $6 \cdot 1(44 / 725)$ \\
\hline Probable infection & $26 \cdot 7(2445)$ & $43 \cdot 1(81 / 188)$ & $13 \cdot 4(97 / 725)$ \\
\hline Previous admission & $5 \cdot 3(484)$ & $14 \cdot 8(68 / 460)$ & $1.6(3 / 188)$ \\
\hline Cardiopulmonary resuscitation & $9.9(903)$ & $19 \cdot 7(69 / 351)$ & $5 \cdot 2(38 / 725)$ \\
\hline
\end{tabular}

sion to an intensive care unit was defined as a previous admission to any type of intensive care unit for a different event from the one being reported in this study.

\section{DATA ON OUTCOME}

Data on outcome included the date of and vital status of patients at discharge from hospital. Mortality in hospital was measured as the overall proportion of patients dying in hospital, including those dying in the intensive care unit.

All data were double entered and verified. Data were also checked for illogical, extreme, or unlikely values and reported back to the intensive care unit for correction when necessary. Statistical significance was determined by $t$ and $\chi^{2}$ tests.

\section{Results}

Eleven intensive care units were recruited in phase I and a further 24 units in phase II. Seven units failed to complete the study and a further two units completed data collection too late for inclusion in these analyses. Results are presented for 11612 admissions to 26 units. The mean number of admissions per unit was 447 (table I). A total of $771(6 \cdot 6 \%)$ admissions were excluded for one or more of the exclusion criteria. Of the remaining 10841 patients, $10806(99.7 \%)$ had data. Only 35 eligible admissions $(0.3 \%)$ were missed because exclusion criteria were misinterpreted or data were genuinely missing.

After confirmation checks with individual intensive care units $455(4 \cdot 2 \%)$ patients were identified as having had two or more admissions (without leaving hospital care). For these patients only data from the first admission were included. Another 419 (3.9\%) patients were confirmed as having been transferred from another unit. For most of these patients data were not available from the first 24 hours of intensive care treatment, so information was lacking for calculation of the APACHE II score and they were excluded. Finally, $814(7 \cdot 5 \%)$ patients had less than eight hours of intensive care treatment before they were discharged from the unit. To ensure compatibility with the original American database used for developing APACHE II (W A Knaus, personal communication) these patients were also excluded. In total 1611 $(14.9 \%)$ of the 10806 patients were excluded, leaving 9195 patients.

Data were complete for all 9195 patients for the sociodemographic factors, coexistent illness, surgical status, diagnosis, and other active problems. For 7305 $(79.4 \%)$ patients all 12 variables of the acute physiology score were measured at least once and a total of 8742 $(95.1 \%)$ patients had three or fewer variables missing. Only $40(0.4 \%)$ patients had all 12 variables missing and they were excluded, leaving 9155 for the analyses of case mix variation (table I). For analyses of outcome a further 56 patients were removed, 37 because their vital status at hospital discharge was missing and 19 because they were still in hospital at the end of data collection for the study; this left 9099 patients.

The sociodemographic characteristics, surgical status, history of chronic conditions, and coexisting active conditions of patients varied between the units (table II).

Table III shows the proportions of non-surgical patients in each system diagnostic category as well as the commonest individual diagnostic categories within each system, applying the American diagnostic categorisation. The total number of cases and the proportion of patients are presented for the complete database, together with the highest and lowest proportions in any individual intensive care unit. Table IV shows the corresponding data for surgical patients. 
TABLE III-System and individual diagnostic categories for non-surgical patients admitted to 26 intensive care units

\begin{tabular}{|c|c|c|c|}
\hline \multirow[b]{2}{*}{ System and individual diagnostic categories } & \multirow[b]{2}{*}{ No $(\%)$ of cases $(n=9155)$} & \multicolumn{2}{|c|}{ Range across units (\%) } \\
\hline & & Highest & Lowest \\
\hline Cardiovascular & $1501(16 \cdot 4)$ & $41 \cdot 7$ & $7 \cdot 5$ \\
\hline Cardiac arrest & $498(5 \cdot 4)$ & $14 \cdot 5$ & 1.5 \\
\hline Multiple trauma & $266(2 \cdot 9)$ & $7 \cdot 4$ & 0 \\
\hline Septic shock/sepsis & $243(2 \cdot 7)$ & 8.0 & $0 \cdot 3$ \\
\hline Gastrointestinal & $218(2 \cdot 4)$ & $4 \cdot 7$ & 0 \\
\hline Infection & $64(0 \cdot 7)$ & $2 \cdot 1$ & 0 \\
\hline Obstruction/perforation & $55(0 \cdot 6)$ & 1.9 & 0 \\
\hline Bleeding & $46(0 \cdot 5)$ & $2 \cdot 0$ & 0 \\
\hline Haematological & $25(0 \cdot 3)$ & 0.9 & 0 \\
\hline Insufficiency/crisis & $15(0 \cdot 2)$ & 0.9 & 0 \\
\hline Renal & $46(0.5)$ & $3 \cdot 7$ & 0 \\
\hline Electrolyte imbalance/acid-base disturbance & $29(0 \cdot 3)$ & $3 \cdot 2$ & 0 \\
\hline Metabolic & $68(0 \cdot 7)$ & $2 \cdot 4$ & 0 \\
\hline Diabetic ketoacidosis & $39(0 \cdot 4)$ & $2 \cdot 1$ & 0 \\
\hline Electrolyte imbalance/acid-base disturbance & $11(0 \cdot 1)$ & 0.9 & 0 \\
\hline Neurological & $858(9 \cdot 4)$ & $23 \cdot 1$ & 2.9 \\
\hline Overdose & $386(4 \cdot 2)$ & $16 \cdot 6$ & 0.9 \\
\hline Head trauma & $167(1 \cdot 8)$ & 6.9 & 0 \\
\hline Seizures & $90(1 \cdot 0)$ & $2 \cdot 5$ & 0 \\
\hline Respiratory & $1208(13 \cdot 2)$ & $26 \cdot 0$ & 6.6 \\
\hline Infection & $374(4 \cdot 1)$ & $14 \cdot 9$ & $1 \cdot 2$ \\
\hline Arrest & $200(2 \cdot 2)$ & 8.8 & 0.7 \\
\hline Asthma/allergic reaction & $181(2 \cdot 0)$ & $4 \cdot 2$ & 0 \\
\hline Burns & $28(0 \cdot 3)$ & $2 \cdot 8$ & 0 \\
\hline
\end{tabular}

TABLE IV-System and individual diagnostic categories for surgical patients admitted to 26 intensive care units

\begin{tabular}{|c|c|c|c|c|}
\hline \multirow[b]{2}{*}{ System and individual diagnostic categories } & \multirow{2}{*}{\multicolumn{2}{|c|}{ No $(\%)$ of cases $(n=9155)$}} & \multicolumn{2}{|c|}{ Range across units (\%) } \\
\hline & & & Highest & Lowest \\
\hline Cardiovascular & & $2462(26.9)$ & 63.5 & $9 \cdot 1$ \\
\hline Peripheral vascular surgery & $1215(13 \cdot 3)$ & & 32.5 & 0 \\
\hline Coronary artery disease & $304(3 \cdot 3)$ & & $36 \cdot 0$ & 0 \\
\hline Multiple trauma & $257(2 \cdot 8)$ & & $12 \cdot 0$ & 0 \\
\hline Gastrointestinal & & $1291(14 \cdot 1)$ & 24.9 & $7 \cdot 3$ \\
\hline Neoplasm & $564(6 \cdot 2)$ & & $14 \cdot 2$ & 0.3 \\
\hline Obstruction/perforation & $405(4 \cdot 4)$ & & $10 \cdot 6$ & 0.6 \\
\hline Bleeding & $194(2 \cdot 1)$ & & $4 \cdot 7$ & $0 \cdot 4$ \\
\hline Haematological & & $5(0.05)$ & 0.5 & 0 \\
\hline Renal & & $212(2 \cdot 3)$ & $9 \cdot 8$ & 0 \\
\hline Neoplasm & $129(1 \cdot 4)$ & & $8 \cdot 8$ & 0 \\
\hline Bleeding & $36(0.4)$ & & 1.4 & 0 \\
\hline Transplantation & $28(0 \cdot 3)$ & & $4 \cdot 7$ & 0 \\
\hline Metabolic & & $13(0 \cdot 1)$ & 0.9 & 0 \\
\hline Neurological & & $182(2.0)$ & $26 \cdot 7$ & 0 \\
\hline Cranial haemorrhage & $61(0.7)$ & & $11 \cdot 3$ & 0 \\
\hline Neoplasm & $39(0.4)$ & & 8.0 & 0 \\
\hline Head trauma & $35(0.4)$ & & $5 \cdot 1$ & 0 \\
\hline Respiratory & & $1037(11 \cdot 3)$ & $26 \cdot 3$ & 3.0 \\
\hline Unplanned support & $454(5 \cdot 0)$ & & $23 \cdot 4$ & 0 \\
\hline Obstruction (actual/potential) & $318(3.5)$ & & 8.8 & 0 \\
\hline Neoplasm & $80(0.9)$ & & 6.5 & 0 \\
\hline Burns & & $1(0.01)$ & 0.01 & 0 \\
\hline
\end{tabular}

The overall mean acute physiology score was 13.9 and varied across the units from $11 \cdot 3$ to $17 \cdot 8$. The overall mean APACHE II score was 17.9 and varied from 14.8 to 22.6 (table V). The rank order to units differed from that obtained when the mean acute physiology score was ranked, which shows the effect of adding the points for age and history of chronic conditions.

Mortality in hospital increased significantly with increasing age $\left(\chi^{2}\right.$ for trend $\left.=352 \cdot 1, \mathrm{df}=1, \mathrm{p}<0.0001\right)$. The mean ( $2 \mathrm{SE})$ age for survivors $(54.1(0.5)$ years) was significantly lower than that for non-survivors $(62.4(0.6)$ years, $\mathrm{p}<0.0001)$. Mortality in hospital for female patients $(27 \cdot 6 \%)$ was similar to that for male patients $(26.7 \%)$. Similarly, mortality in hospital for white patients $(27.0 \%)$ was similar to that for nonwhite patients $(29 \cdot 7 \%)$.

Mortality in hospital was significantly higher for the 2029 patients with a history of chronic disease $(38.5 \%)$ than for the 7070 patients without such a history $(23.8 \%, p<0.0001)$. Significant differences existed for each of the chronic diseases, the most noticeable difference being for the 146 patients with a history of hepatic disease compared with those without hepatic disease $(59.6 \%$ v $26.5 \%, \mathrm{p}<0.0001)$.

Mortality in hospital was significantly lower for surgical patients than for non-surgical patients $(19 \cdot 1 \%$ $v 37.6 \%, \mathrm{p}<0.0001)$. Patients who had emergency surgery had significantly higher mortality in hospital than had patients who underwent elective surgery $(29.8 \% v 10.2 \%, \mathrm{p}<0.0001)$. The difference between surgical and non-surgical groups was greatest in four of the system diagnostic categories: cardiovascular $(18.3 \%$ v $43.2 \%, \mathrm{p}<0.0001)$; gastrointestinal $(27.5 \%$ v $57.6 \%, \mathrm{p}<0.0001)$; respiratory $(10.6 \%$ v $35.3 \%$, $\mathrm{p}<0.0001)$; and $\operatorname{renal}(13.2 \%$ v $37.0 \%, \mathrm{p}<0.0001)$ (table VI).

Mortality in hospital was not significantly related either to malignant cancer as an active medical problem $(28.4 \% v 26.8 \%)$ or to a previous admission to an intensive care unit $(25.6 \% v 27 \cdot 1 \%)$. In contrast, hospital mortality in patients with a probable infection on admission and in those who had had cardiopulmonary resuscitation in the 24 hours before admission was significantly higher than mortality in hospital in patients without these problems $(42.8 \% v 21.3 \%$ for infection, $\mathrm{p}<0.0001$, and $56.8 \% v 23.8 \%$ for cardiopulmonary resuscitation, $\mathrm{p}<0.0001$ ).

Mortality in hospital increased highly significantly with increasing acute physiology and APACHE II scores (table VII). The mean (2SE) acute physiology and APACHE II scores for survivors were significantly lower than those for non-survivors $(11.7(0.2) v 19.9$ $(0.3)$ for acute physiology score, $\mathrm{p}<0.0001 ; 15.2(0.2)$ $v 25 \cdot 1(0 \cdot 3)$ for APACHE II score, $\mathrm{p}<0 \cdot 0001)$.

\section{Discussion}

In this comparison of 26 intensive care units in Britain and Ireland many important differences existed in the case mix variables measured. A comparison of these results with those of previous studies from single units in the United Kingdom ${ }^{11-17}$ is only possible on the assumption that the absence of standardised definitions and methods of data collection can be ignored. For all case mix variables where comparisons could be drawn (age, sex, surgical status, and APACHE II score), however, the differences observed in this study were greater than those between the units in the individual studies.

The potential importance of these differences in case mix was illustrated by the association between the case mix factors investigated and subsequent mortality in hospital. This mortality was significantly associated with all the case mix factors investigated apart from sex, race, the presence or absence of malignant

TABLE V-Mean APACHE II scores and range in patients admitted to 26 intensive care units in Britain and Ireland

\begin{tabular}{|c|c|c|c|}
\hline \multirow{2}{*}{$\begin{array}{l}\text { Intensive care } \\
\text { unit (case No) }\end{array}$} & \multirow[b]{2}{*}{ Mean } & \multicolumn{2}{|c|}{ Range } \\
\hline & & High & Low \\
\hline 15 & 14.8 & 38 & 0 \\
\hline 20 & 15.5 & 47 & 3 \\
\hline 24 & $15 \cdot 7$ & 52 & 0 \\
\hline 26 & $16 \cdot 4$ & 47 & 0 \\
\hline 12 & 16.5 & 40 & 0 \\
\hline 13 & $17 \cdot 2$ & 39 & 0 \\
\hline 23 & 17.3 & 50 & 0 \\
\hline 16 & $17 \cdot 4$ & 45 & 0 \\
\hline 19 & 17.4 & 38 & 3 \\
\hline 6 & 17.7 & 43 & 2 \\
\hline 4 & 17.8 & 50 & 0 \\
\hline 21 & 17.9 & 40 & 1 \\
\hline $\begin{array}{r}1 \\
8\end{array}$ & 18.0 & 50 & 0 \\
\hline 3 & 18.3 & 56 & 0 \\
\hline 5 & $18 \cdot 3$ & 51 & 0 \\
\hline 17 & 18.3 & 54 & 1 \\
\hline 11 & 18.5 & 44 & 0 \\
\hline 10 & 18.8 & 42 & 2 \\
\hline 7 & 18.9 & 44 & 3 \\
\hline 18 & $19 \cdot 2$ & 44 & 3 \\
\hline 9 & $19 \cdot 3$ & 43 & 7 \\
\hline 22 & $19 \cdot 4$ & 51 & 1 \\
\hline 25 & 19.6 & 55 & 3 \\
\hline 14 & 19.8 & 45 & 2 \\
\hline 1 & 21.0 & 49 & 4 \\
\hline 2 & 22.6 & 54 & 1 \\
\hline
\end{tabular}


TABLE VI-System diagnostic categories and hospital mortality in surgical and non-surgical patients

\begin{tabular}{|c|c|c|c|}
\hline $\begin{array}{l}\text { System diagnostic } \\
\text { category }\end{array}$ & $\begin{array}{c}\text { No of } \\
\text { admissions }\end{array}$ & $\begin{array}{l}\text { No of } \\
\text { deaths }\end{array}$ & $\begin{array}{c}\text { Hospital mortality } \\
(\%)(95 \% \text { confidence } \\
\text { intervals })\end{array}$ \\
\hline \multicolumn{4}{|c|}{ Surgical patients } \\
\hline $\begin{array}{l}\text { Cardiovascular } \\
\text { Gastrointestinal } \\
\text { Neurological } \\
\text { Respiratory } \\
\text { Renal } \\
\text { Haematological } \\
\text { Metabolic } \\
\text { Burns }\end{array}$ & $\begin{array}{r}2457 \\
1286 \\
180 \\
1030 \\
212 \\
5 \\
13 \\
1\end{array}$ & $\begin{array}{r}450 \\
354 \\
45 \\
109 \\
28 \\
2 \\
2 \\
1\end{array}$ & $\begin{array}{l}18.3(16.8 \text { to } 19.8) \\
27.5(25.1 \text { to } 29.9) \\
25.0(18.7 \text { to } 31.1) \\
10.6(8.7 \text { to } 12.5) \\
13.2(8.6 \text { to } 17.8) \\
40.0(0 \text { to } 82.9) \\
15.4(0 \text { to } 35.0) \\
100.0\end{array}$ \\
\hline Total & 5184 & 991 & $19.1(18.0$ to 20.2$)$ \\
\hline \multicolumn{4}{|c|}{ Non-surgical patients } \\
\hline $\begin{array}{l}\text { Cardiovascular } \\
\text { Gastrointestinal } \\
\text { Neurological } \\
\text { Respiratory } \\
\text { Renal } \\
\text { Haematological } \\
\text { Metabolic } \\
\text { Burns }\end{array}$ & $\begin{array}{r}1489 \\
217 \\
884 \\
1200 \\
46 \\
25 \\
68 \\
26\end{array}$ & $\begin{array}{r}643 \\
125 \\
225 \\
424 \\
17 \\
11 \\
8 \\
17\end{array}$ & $\begin{array}{l}43.2(40.7 \text { to } 45 \cdot 7) \\
57.6(51.0 \text { to } 64.2) \\
26.7(23.7 \text { to } 29 \cdot 7) \\
35.3(32.6 \text { to } 38.0) \\
37.0(23.0 \text { to } 51 \cdot 0) \\
44.0(24.5 \text { to } 63.5) \\
11.8(4.1 \text { to } 19.5) \\
65.4(4.71 \text { to } 83.7)\end{array}$ \\
\hline Total & 3915 & 1470 & $37 \cdot 6(36 \cdot 1$ to $39 \cdot 1)$ \\
\hline \multirow{2}{*}{\multicolumn{4}{|c|}{$\begin{array}{l}\text { Surgical } v \text { non-surgical } \chi^{2}=384 \cdot 0, \mathrm{df}=1, \mathrm{p}<0.0001 \\
\text { All system diagnostic categories } \chi^{2}=635 \cdot 9, \mathrm{df}=15, \mathrm{p}<0.0001 . \\
\text { TABLE vII-Acute physiology score, APACHE II score, and hospital } \\
\text { mortality }\end{array}$}} \\
\hline & & & \\
\hline & $\begin{array}{c}\text { No of } \\
\text { admissions }\end{array}$ & $\begin{array}{l}\text { No of } \\
\text { deaths }\end{array}$ & $\begin{array}{l}\text { Hospital mortality } \\
\text { (\%) (95\% confidence } \\
\text { intervals) }\end{array}$ \\
\hline \multicolumn{4}{|c|}{ Acute physiology score: } \\
\hline $\begin{array}{c}0-4 \\
5-9 \\
10-14 \\
15-19 \\
20-24 \\
25-29 \\
30-34 \\
\geqslant 35\end{array}$ & $\begin{array}{r}590 \\
2322 \\
2700 \\
1612 \\
893 \\
557 \\
248 \\
177\end{array}$ & $\begin{array}{r}32 \\
196 \\
489 \\
558 \\
470 \\
385 \\
179 \\
152\end{array}$ & $\begin{array}{c}5.4(3.6 \text { to } 7 \cdot 2) \\
8.4(7.3 \text { to } 9.5) \\
18.1(16.6 \text { to } 19 \cdot 6) \\
34.6(32.3 \text { to } 36.9) \\
52.6(49.3 \text { to } 55.9) \\
69.1(65.3 \text { to } 72.9) \\
72.2(66.6 \text { to } 72 \cdot 8) \\
85.9(80.8 \text { to } 91.0)\end{array}$ \\
\hline \multicolumn{4}{|c|}{$\chi^{2}$ for trend $=1990.4, \mathrm{df}=1, \mathrm{p}<0.0001$} \\
\hline $\begin{array}{c}0-4 \\
5-9 \\
10-14 \\
15-19 \\
20-24 \\
25-29 \\
30-34 \\
\geqslant 35 \\
\chi^{2} \text { for trend }=2304 .\end{array}$ & $\begin{array}{r}279 \\
1109 \\
2202 \\
2143 \\
1520 \\
883 \\
509 \\
454 \\
<0.0001\end{array}$ & $\begin{array}{r}1 \\
44 \\
215 \\
403 \\
576 \\
502 \\
355 \\
365\end{array}$ & $\begin{array}{l}0.4(0 \text { to } 1 \cdot 1) \\
4.0(2.8 \text { to } 5 \cdot 2) \\
9.8(8.6 \text { to } 11 \cdot 0) \\
18.8(17 \cdot 1 \text { to } 20.5) \\
37.9(35.5 \text { to } 40.3) \\
56.9(53.6 \text { to } 60 \cdot 2) \\
69 \cdot 7(65.7 \text { to } 73.9) \\
80.4(76.7 \text { to } 84 \cdot 1)\end{array}$ \\
\hline
\end{tabular}

cancer, and the presence or absence of a previous admission to an intensive care unit.

Such univariate analyses, however, take no account of possible confounding variables. For example, the twofold variation in mortality in hospital associated with patients with a history of hepatic disease might be because such patients are older. This example illustrates the futility of drawing inferences from comparisons between units of crude outcome statistics.

Standardised collection of case mix data and subsequent adjustment for case mix differences are essential when comparing outcomes. To adjust for possible confounding variables multiple logistic regression analyses must be undertaken to investigate the relation between combinations of case mix factors and hospital

\section{Clinical implications}

- More information is needed on the outcome of intensive care in the United Kingdom

- This study found that the case mix of patients varied greatly between intensive care units

- Mortality in hospital was significantly associated with patients' age, severity of illness, diagnosis, surgical status, and history of chronic conditions

- Differences in case mix must be taken into account when comparing outcome in intensive care units mortality. To our knowledge, this has not been done for adult patients in intensive care units in the United Kingdom. Such analyses, however, have been undertaken in the United States based on over 5000 patients admitted to intensive care units. This resulted in the development of the American APACHE II equation to predict the risk of dying in hospital. ${ }^{4}$ The equation described the relation between case mix, appropriately weighted, and hospital mortality. Case mix was defined in terms of the patients' illness severity (APACHE II score), surgical status (emergency surgical $v$ elective surgical/non-surgical), and diagnosis (principal system or individual diagnostic category leading to admission to an intensive care unit). The equation accurately predicts mortality for the American data from which it was derived. ${ }^{5}$

It would be unwise to apply the American equation in the United Kingdom until its validity has been shown. This has been one of the objectives of the Intensive Care Society's APACHE II study in Britain and Ireland and is described in the next paper. The availability of a validated method of adjusting for case mix provides a way of making meaningful outcome comparisons of intensive care units. Even without absolute standards, comparative data would help units assess and audit their work.

This work was supported by grants from the Medical Research Council, the King's Fund for Health Services Development, the Intensive Care Society, and the Medical Research Fund. We acknowledge the directors and staff of the participating general intensive care units for collecting the data: Bristol Royal Infirmary; Broomfield Hospital, Chelmsford; Freeman Hospital, Newcastle; Glasgow Royal Infirmary; Lewisham Hospital; Morriston Hospital, Swansea; Royal Devon and Exeter Hospital; Western Infirmary, Glasgow; University Hospital of South Manchester; Dudley Road Hospital, Birmingham; Northampton General Hospital; Broadgreen Hospital, Liverpool; John Radcliffe Hospital, Oxford; Sunderland District General Hospital; Salisbury General Hospital; Victoria Infirmary, Glasgow; Western General Hospital, Edinburgh; Beaumont Hospital, Dublin; Royal Cornwall Hospital, Truro; University College Hospital, London; East Glamorgan Hospital; Royal Sussex County Hospital, Brighton; Princess Margaret Hospital, Swindon; Newcastle General Hospital; Countess of Chester Hospital; and Royal Infirmary of Edinburgh.

\section{Appendix}

\section{APACHE II METHOD}

Table VIII shows the assignment of points for the acute physiology score, one component of the APACHE II score.

Rectal temperature-Measurements of temperature from sites other than the rectum (oesophagus, tympanic membrane, nasopharynx, and pulmonary artery) were considered to be core temperatures. To temperature measurements at the oral site half a degree was added and to temperature measurements at peripheral sites (axilla and groin) one degree was added before points were assigned.

Mean blood pressure-Mean arterial pressure was calculated as the sum of twice the diastolic value plus the systolic value divided by three.

Oxygenation-When the oxygen concentration was greater than or equal to $50 \%$ points were assigned to the alveolar to arterial oxygen tension difference. This was calculated as (percentage oxygen concentration $\times 713$ )-arterial oxygen tension $(\mathrm{mm} \mathrm{Hg})$ - arterial carbon dioxide tension $(\mathrm{mm} \mathrm{Hg})$. When the oxygen concentration was less than $50 \%$, points were assigned to the lowest arterial oxygen tension.

Arterial $p H$ was measured in the same blood sample used to measure oxygenation. Concentrations of hydrogen ions were converted to $\mathrm{pH}$ values by taking the negative logarithm of the concentration of hydrogen ions.

Serum creatinine-Measurements in $\mu \mathrm{mol} / /$ were converted to $\mathrm{mg} / 100 \mathrm{ml}$ by dividing by 88.4 . Points for serum creatinine concentration were doubled in the presence of acute renal failure. Acute renal failure was defined as a serum creatinine value of greater than $1.4 \mathrm{mg} / 100 \mathrm{ml}$ during the previous $24-48$ 


\begin{tabular}{|c|c|c|c|c|c|c|c|c|c|}
\hline & 4 & 3 & 2 & 1 & 0 & 1 & 2 & 3 & 4 \\
\hline $\begin{array}{l}\text { Rectal temperature }\left({ }^{\circ} \mathrm{C}\right) \\
\text { Mean blood pressure }\end{array}$ & $\geqslant 41.0$ & $39 \cdot 0-40 \cdot 9$ & & $38 \cdot 5-38 \cdot 9$ & $36 \cdot 0-38 \cdot 4$ & $34 \cdot 0-35 \cdot 9$ & $32 \cdot 0-33 \cdot 9$ & $30 \cdot 0-31 \cdot 9$ & $\leqslant 29.9$ \\
\hline $\begin{array}{l}(\mathrm{mm} \mathrm{Hg}) \\
\text { Heart rate (ventricular }\end{array}$ & $\geqslant 160$ & $130-159$ & $110-129$ & & 70-109 & & $50-69$ & & $\leqslant 49$ \\
\hline $\begin{array}{l}\text { response/min) } \\
\text { Respiratory rate (breaths/ }\end{array}$ & $\geqslant 180$ & $140-179$ & $110-139$ & & $70-109$ & & $55-69$ & $40-54$ & $\leqslant 39$ \\
\hline $\begin{array}{l}\text { min, spontaneous or } \\
\text { mechanical) } \\
\text { Oxygenation }(\mathrm{mm} \mathrm{Hg})\end{array}$ & $\geqslant 50$ & $35-49$ & & $25-34$ & $12-24$ & $10-11$ & $6-9$ & & $\leqslant 5$ \\
\hline $\begin{array}{l}\text { I }(\geqslant 50 \%) \\
\text { II }(<50 \%)\end{array}$ & $\geqslant 500$ & $350-499$ & $200-349$ & & $\begin{array}{l}<200 \\
>70\end{array}$ & $61-70$ & & $55-60$ & $<55$ \\
\hline $\begin{array}{l}\text { Arterial } \mathrm{pH} \\
\text { Serum sodium }(\mathrm{mmol} / \mathrm{l}) \\
\text { Serum potassium }(\mathrm{mmol} / \mathrm{l})\end{array}$ & $\begin{array}{l}\geqslant 7 \cdot 70 \\
\geqslant 180 \\
\geqslant 7 \cdot 0\end{array}$ & $\begin{array}{c}7 \cdot 60-7 \cdot 69 \\
160-179 \\
6 \cdot 0-6 \cdot 9\end{array}$ & $155-159$ & $\begin{array}{c}7 \cdot 50-7 \cdot 59 \\
150-154 \\
5 \cdot 5-5 \cdot 9\end{array}$ & $\begin{array}{c}7 \cdot 33-7 \cdot 49 \\
130-149 \\
3 \cdot 5-5 \cdot 4\end{array}$ & $3 \cdot 0-3 \cdot 4$ & $\begin{array}{c}7 \cdot 25-7 \cdot 32 \\
120-129 \\
2 \cdot 5-2 \cdot 9\end{array}$ & $\begin{array}{l}7 \cdot 15-7 \cdot 24 \\
111-119\end{array}$ & $\begin{array}{l}<7 \cdot 15 \\
\leqslant 110 \\
<2 \cdot 5\end{array}$ \\
\hline $\begin{array}{l}\text { Serum creatinine } \\
(\mathrm{mg} / 100 \mathrm{ml})\end{array}$ & $\geqslant 3.5$ & $2 \cdot 0-3 \cdot 4$ & $1.5-1.9$ & & $0 \cdot 6-1 \cdot 4$ & $50-5 \cdot 4$ & $<0.6$ & & \\
\hline $\begin{array}{l}\text { Haematocrit } \\
\text { White blood cell count }\end{array}$ & $\geqslant 60$ & & $50-59 \cdot 9$ & $46-49 \cdot 9$ & $30-45 \cdot 9$ & & $20-29 \cdot 9$ & & $<20$ \\
\hline $\begin{array}{l}\left(\times 10^{3} / \mathrm{ml}^{3}\right) \\
\text { Glasgow coma score }\end{array}$ & $\begin{array}{r}\geqslant 40 \\
15\end{array}$ & & $20-39 \cdot 9$ & $15-19 \cdot 9$ & $3-14 \cdot 9$ & & $1-2.9$ & & $<1$ \\
\hline
\end{tabular}

TABLE IX-Points assigned to aged and chronic disease as part

\begin{tabular}{lc}
\hline & Score \\
\hline Age (years): & \\
$<45$ & 0 \\
$45-54$ & 2 \\
$55-64$ & 3 \\
$65-74$ & 5 \\
$\geqslant 75$ & 6 \\
History of chronic conditions: & \\
$\begin{array}{l}\text { None } \\
\text { Present: } \\
\text { Elective surgical patient: }\end{array}$ & 2 \\
Emergency surgical or & \\
non-surgical patient & 5 \\
\hline
\end{tabular}
of the APACHE II score

hours associated with oliguria. Oliguria was defined as a urine output of less than $135 \mathrm{ml}$ over eight consecutive hours that was not caused by absence or obstruction of a urinary catheter or by incontinence.

Haematocrit - When haematocrit values were not available points were assigned to the haemoglobin concentration multiplied by three.

Glasgow coma score ${ }^{20}$ was determined in every patient. Clinical judgment was used to estimate the score in patients who were sedated, intubated, or paralysed. According to the original APACHE II guidelines, the score was considered to be normal (15) and zero points were assigned if at the time of assessment the patient was at a decreased level of consciousness owing to secondary sedation. This rule did not apply to patients who were sedated having taken an overdose.

TABLE X-Diagnostic categories used in the United States and in Britain and Ireland

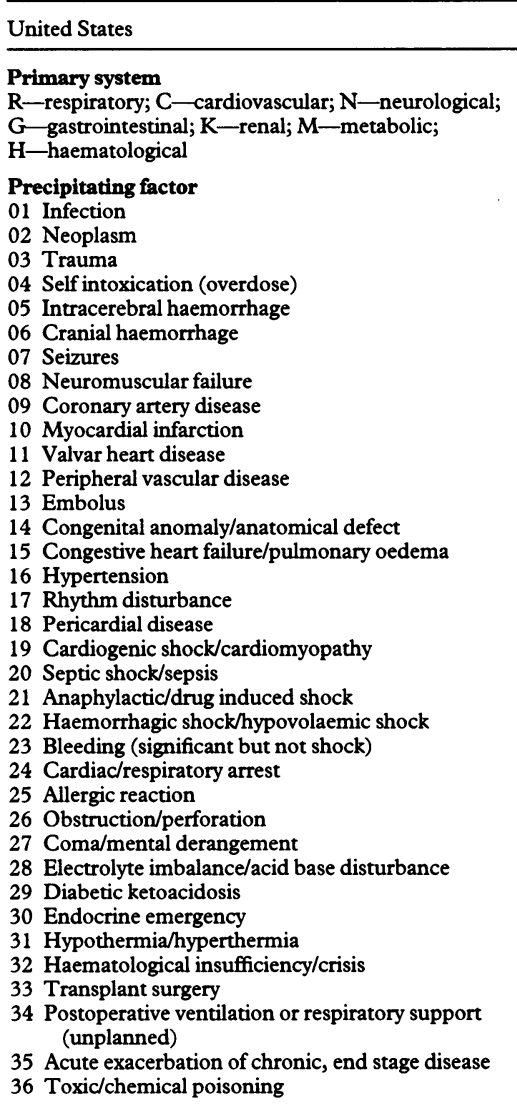

\section{Respiratory}

01 Aspiration/poisoning/toxic

$02 \mathrm{Asthma/allergy}$

03 Chronic obstructive pulmonary (airways) disease

04 Pulmonary infection

05 Insufficiency after surgery

06 Pulmonary embolus

07 Pulmonary neoplasm

08 Pulmonary oedema (non-cardiogenic)

09 Respiratory arrest

10 Respiratory observation

Cardiovascular

11 Aortic (including thoracic) aneurysm

12 Congestive cardiac failure

13 Coronary artery disease/myocardial infarction

14 Heart valve disease

15 Hypertension

16 Pericardial disease

17 Peripheral vascular disease

18 Rhythm disturbance

19 Shock-anaphylactic

20 Shock-cardiogenic

21 Shock-hypovolaemic

22 Bleeding but not shock

23 Sepsis

23 Sepsis

25 Trauma-multiple

26 Trauma-simple

Neurological

27 Trauma-head injury alone

28 Intracranial bleeding

29 Central nervous system infection

30 Neoplasm

31 Neuromuscular failure

32 Seizures/fits

32 Seizures/fits

Gastrointestina

34 Bleeding

35 Hepatic/pancreatic disease

36 Hepatic/pan

37 Peoplasm

37 Perfor

38 Neoplasm

39 Transplant operation

Metabolic

40 Overdose

41 Diabetic ketoacidosis

If not applicable assign to one of seven general system diagnostic categories: respiratory, cardiovascular neurological, gastrointestinal, renal, metabolic, or haematological
Table IX shows points assigned for age and history of chronic conditions as part of the APACHE II score. There are precise criteria for defining the presence of chronic insufficiency.

Liver/gastrointestinal insufficiency is cirrhosis in a biopsy specimen and documented portal hypertension; episodes of past upper gastrointestinal bleeding attributed to portal hypertension; or previous episodes of hepatic failure, coma, or encephalopathy.

Cardiovascular insufficiency is angina or symptoms at rest or minimal exertion (getting dressed or self care) (New York Heart Association's class IV); severe coronary artery disease; severe cardiomyopathy; or severe valvar heart disease.

Respiratory insufficiency is chronic restrictive, obstructive, or vascular disease in the lung resulting in severe restriction on exercise (for example, an inability to climb stairs or perform household duties) or documented chronic hypoxia, hypercapnia, secondary polycythaemia, severe pulmonary hypertension ( $>40 \mathrm{~mm} \mathrm{Hg}$ ), or respirator dependency (for example, active respiratory disease, sarcoidosis, interstitial fibrosis, tuberculosis, chronic obstructive pulmonary disease).

Renal insufficiency is present if a patient is receiving long term haemodialysis or peritoneal dialysis.

Immune insufficiency is present if a patient is receiving treatment that suppresses resistance to infection (for example, immunosuppression); if a patient is currently receiving high dose steroid treatment (for example, methylprednisolone ( $\geqslant 15 \mathrm{mg} / \mathrm{kg}$ ) or its equivalent daily for five or more days); if a patient has received active chemotherapy or radiotherapy within one year of the study; if a patient received chemotherapy or radiotherapy at any time in the past for Hodgkin's diease or non-Hodgkin's lymphoma; if a patient has a documented immunohumoral or cellular immune deficiency state; or if a patient has a disease that is sufficiently advanced to suppress resistance to infection (for example, leukaemia, lymphoma, AIDS, diffuse metastatic cancer). Presence of the chronic insufficiency must be evident before the current admission to hospital

Points for chronic disease were assigned to patients suffering from insufficiency of at least one of the defined systems. When insufficient information was available the patient was assumed not to have a history of chronic disease.

Patients admitted directly to an intensive care unit from an operating theatre or recovery room (including procedures undergone in the $x$ ray department or cases when anaesthesia was induced but the operation was not started for other reasons) were defined as surgical admissions. All other admissions were defined as non-surgical.

Emergency surgery was that required immediately to prevent a life threatening complication. Elective surgery was scheduled, the patient being able to wait, but it may still entail serious problems and procedures.

DIAGNOSTIC CATEGORIES

Table $\mathrm{X}$ shows the diagnostic categories used in the United States and in Britain and Ireland.

1 King's Fund Centre for Health Care Development. Intensive care in the United Kingdom. Report from the Kings Fund Panel. Anaesthesia 1989;44: 428-31.

2 Draper EA, Wagner DP, Knaus WA. The use of intensive care: a comparison 
of a university and community hospital. Health Care Financial Review 1981;3:49-64.

3 Knaus WA, Draper EA, Wagner DP, Zimmerman JE, Birnbaum ML, Cullen DJ, et al. Evaluating outcome from intensive care: a preliminary multihospital comparison. Crit Care Med 1982;10:491-6.

4 Knaus WA, Draper EA, W/agner DP, Zimmerman JE. APACHE II: A severity of disease classification system. Crit Care Med 1985;13:818-29.

5 Knaus WA, Draper EA, Wagner DP, Zimmerman JE. An evaluation of outcome from intensive care in major medical centers. Ann Intern Med $1986 ; 104: 410-8$.

6 Marsh HM, Krishan I, Naessens JM, Strickland RA, Gracey DR, Campion $\mathrm{ME}$, et al. Assessment of prediction of mortality by using the APACHE II scoring system in intensive care units. Mayo Clin Proc 1990;65:1549-57.

7 Eagle KA, Mulley AG, Field TS, Skates S, Bero G, Clark CE, et al. Variation in intensive care unit practices in two community hospitals. Med Care 1991;29:1237-45.

8 French Multicentre Group of Intensive Care Unit Research and the INSERM Unit 169 of Statistical and Epidemiological Studies. Description of various types of intensive and intermediate care units in France. Intensive Care Medicine 1989;15:260-5.

9 Mahul P, Perrot D, Tempelhoff G, Gaussorgues P, Jospe R, Ducreux JC, et al. Short- and long-term prognosis, functional outcome following ICU for elderly. Intensive Care Medicine 1991;17:7-10.

10 Dragsted L, Jorgensen J, Jensen NH, Bonsing E, Jacobsen E, Knaus WA, al. Interhospital comparisons of patient outcome from intensive care: Importance of lead-time bias. Crit Care Med 1989;17:418-22.

11 Bion JF, Aitchison TC, Edlin SA, Ledingham IMcA. Sickness scoring and response to treatment as predictors of outcome from critical illness. Intensive Care Medicine 1988;14:167-72.

12 Chisakuta AM, Alexander JP. Audit in intensive care. The APACHE II classification of severity of disease. Ulster Med f 1990;59:161-7.

13 Gilbertson AA, Smith JM, Mostafa SM. The cost of an intensive care unit: a prospective study. Intensive Care Medicine 1991;17:204-8.

14 Marks RJ, Simons RS, Blizzard RA, Browne DRG. Predicting outcome in intensive therapy units-a comparison of APACHE II with subjective assessments. Intensive Care Medicine 1991;17:159-63.

15 Ridley S, Jackson R, Findlay J, Wallace P. Long term survival after intensive care. $B M \mathcal{F} 1990 ; 301: 1127-30$.

16 Shiell AM, Griffiths RD, Short AIK, Spiby J. An evaluation of the costs and outcome of adult intensive care in two units in the UK. Clinical Intensive Care 1990;1:256-61.

17 Waters $M$, Nightingale $P$, Edwards JD. A critical study of the APACHE scoring system using earlier data collection. Arch Emerg Med 1990;7:16-20.

18 Lemeshow S, Teres D, Pastides H, Spitz Avrunin J, Steingrub JS. A method for predicting survival and mortality of ICU patients using objectively derived weights. Crit Care Med 1985;13:519-25.

19 Lemeshow S, Teres D, Spitz Avrunin J, Gage RW. Refining intensive care unit outcome prediction by using changing probabilities of mortality. Crit Care Med 1988;16:470-7.

20 Teasdale G, Jennett B. Assessment of coma and impaired consciousness. A practical scale. Lancet 1974;11:81-4.

(Accepted 23 fuly 1993)
Department of Public

Health and Primary Care,

University of Oxford,

Gibson Laboratories

Building, Radcliffe

Infirmary, Oxford

OX2 6HE

K M Rowan, research fellow

M P Vessey, professor of

social and community medicine

Nuffield Department of

Anaesthetics, University of

Oxford, Radcliffe

Infirmary, Oxford

OX2 6HE

J H Kerr, consultant

anaesthetist

Intensive Therapy Unit, Morriston Hospital,

Swansea SA9 6NL

E Major, director

Health Promotion Sciences Unit, Department of Public Health and Policy, London School of Hygiene and Tropical Medicine, London WC1E 7HT $\mathrm{K}$ McPherson, professor of public health epidemiology

Intensive Care Unit, Broomfield Hospital, Chelmsford, Essex

CM1 5ET

A Short, director

Correspondence to:

Dr Rowan.

$B M \mp 1993 ; 307: 977-81$

\title{
Intensive Care Society's APACHE II study in Britain and Ireland-II: Outcome comparisons of intensive care units after adjustment for case mix by the American APACHE II method
}

\author{
K M Rowan, J H Kerr, E Major, K McPherson, A Short, M P Vessey
}

Abstract

Objectives-To compare outcome between intensive care units in Britain and Ireland both before and after adjustment for case mix with the American APACHE II method and to validate the American APACHE II method in Britain and Ireland.

Design-Prospective, cohort study of consecutive admissions to intensive care units.

Setting - 26 general intensive care units in Britain and Ireland.

Subjects -8796 admissions to the study intensive care units.

Main outcome measure-Death or survival at discharge from intensive care unit and hospital.

Results-At discharge from both intensive care unit and hospital there was a greater than twofold variation in crude mortality between the 26 units. After adjustment for case mix, variations in mortality were still apparent. For four intensive care units the observed numbers of deaths were significantly different from the number predicted by the American APACHE II equation. The overall goodness of fit, or predictive ability, of the APACHE II equation for the British and Irish data was good, being only slightly inferior to that obtained when the equation was tested on the data from which it had been derived. When patients were grouped by various factors such as age and diagnosis, the equation did not adjust across the subgroups in a uniform manner.

Conclusions-The American APACHE II equation did not fit the British and Irish data. Use of the American equation could be of advantage or disadvantage to individual intensive care units, depending on the mix of patients treated.

\section{Introduction}

Knaus et al described an equation to predict in-hospital mortality in critically ill patients in intensive care. ${ }^{1}$ Multiple logistic regression analyses of case mix and outcome data collected on 5030 patients admitted to intensive care units in the United States resulted in the development of the APACHE II equation. The equation described the relation of case mix, appropriately weighted, to hospital mortality. Case mix was defined by the patient's severity of illness (APACHE II score), surgical status (emergency surgical or elective surgical/non-surgical), and diagnosis (principal system or individual diagnostic category leading to admission to an intensive care unit).

One of the proposed uses of the APACHE II equation was to "prognostically stratify acutely ill patients" to "compare the efficacy of intensive care in different hospitals." The developers applied the equation to the database from which it was derived, both to test the predictive ability of the equation and to compare outcomes between intensive care units from 13 tertiary care hospitals in the United States. They calculated mortality ratios (observed hospital mortality divided by predicted hospital mortality) for each intensive care unit. One unit had significantly better results ( $41 \%$ fewer deaths than predicted) and one unit had significantly inferior results $(58 \%$ more deaths than predicted)..$^{23}$ They subsequently applied the American equation to intensive care units in two hospitals in New Zealand ${ }^{4}$ and more recently to units in six hospitals in Japan. ${ }^{5}$ In both studies they found that observed mortality did not differ significantly from that predicted by the American equation.

Mortality ratios estimated by the APACHE II equation have been used by other workers to audit their individual intensive care unit performance ${ }^{6-8}$ and to compare outcomes for surgical and non-surgical patients from four intensive care units in two hospitals. Two of these studies were undertaken in single, intensive care units in the United Kingdom. ${ }^{67}$

Inferences cannot be made from differences in mortality between British intensive care units with the American equation to adjust for case mix until the predictive ability of the equation (not only in terms of its overall goodness of fit to British data but also in terms of its ability to account for differences in mortality between subgroups) has been shown. We report the results of comparisons of outcome between 26 intensive care units in Britain and Ireland both before and after adjustment for case mix by the 